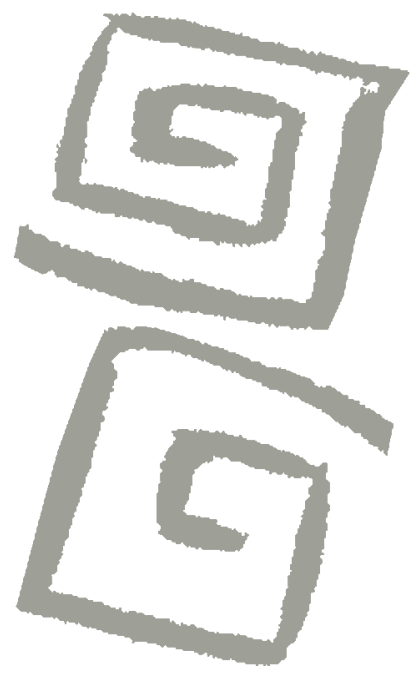

\title{
El servicio de sanidad militar en el proceso de modernización, burocratización y profesionalización del ejército argentino (1888-1938)
}

${ }^{1}$ Doctor en Antropología Social. Investigador independiente, Consejo Nacional de Investigaciones Científicas y Técnicas. Profesor titular (ordinario), Facultad de Humanidades y Ciencias de la Educación, Universidad Nacional de La Plata, La Plata, Argentina. $\triangle$ (iD)

\author{
The military health service in the process \\ of modernization, bureaucratization and \\ professionalization of the Argentine Army (1888-1938)
}

Germán Soprano ${ }^{1}$

RESUMEN Hacia fines del siglo XIX y principios del siglo XX se inició la modernización, burocratización y profesionalización del Ejército Argentino. Como resultado de ese proceso se conformaron las divisiones del Ejército, esto es, organizaciones militares autónomas entre sí, compuestas por unidades de diferentes armas, elementos de apoyo de combate y de servicios. Entre estos últimos estaba el de sanidad militar, que actuaba en las unidades operativas de los distritos militares para el reconocimiento de los ciudadanos para el Servicio Militar Obligatorio y en los hospitales militares. Este artículo tiene por objetivos: 1) caracterizar ese proceso en sus relaciones con las concepciones de la defensa, organización, funciones y despliegue territorial del Ejército; 2) analizar, en ese marco, la conformación del servicio de sanidad militar entre 1888, con la sanción de la Ley Orgánica del Cuerpo de Sanidad del Ejército y la Armada, y 1938, con los cambios en el diseño orgánico del Ejército en vísperas de la Segunda Guerra Mundial.

PALABRAS CLAVES Historia del Siglo XIX; Hospitales Militares; Personal del Ejército; Modernización; Argentina.

\begin{abstract}
At the end of the 19th and beginning of the 20th century, a process of modernization, bureaucratization and professionalization of the Argentine Army was initiated. As a result of this process, Army divisions were formed, which are autonomous military organizations composed of units of various weapons, combat support elements and services. Included among the latter was the military health service, which acted both in the operational units of the military districts in order to incorporate citizens into the Compulsory Military Service as well as in military hospitals. This article aims to: 1) characterize this process in relation to the concepts of defense, organization, functions and territorial deployment of the Army; 2) analyze, within that framework, the formation of the military health service between 1888 -when the Organic Law of the Sanitary Corp of the Army and the Navy was sanctioned - and 1938 - when the Army's organic design was changed on the eve of the Second World War.
\end{abstract}

KEY WORDS History, 19th Century; Hospitals, Military; Personnel, Army; Modernization; Argentina. 


\section{INTRODUCCIÓN}

Entre fines del siglo XIX y principios del siglo XX se inició un proceso de modernización, burocratización y profesionalización del Ejército Argentino que expresó el paso del Ejército de Línea a la conformación del Ejército moderno. Los historiadores que estudian el Ejército analizaron esos cambios doctrinarios, organizacionales y funcionales que se desarrollaron -no sin conflictos, marchas y contramarchasen esos años comprendiendo sus relaciones con la política y la sociedad argentina, pero también reconociendo la especificidad de las lógicas y prácticas castrenses que los orientaban y/o determinaban. Como resultado de ese proceso se crearon, en 1884, el Estado Mayor del Ejército y, en 1900, la Escuela Superior de Guerra. En 1989, se aprobó la Ley 3679 de Código de Justicia Militar y, en 1901, la Ley 4031 de Servicio Militar Obligatorio, que definió las características de esta prestación militar ciudadana, prescribió la conformación de las reservas y dividió el territorio nacional en regiones militares que constituirían divisiones de Ejército. También se sancionaron leyes que, entre otras cuestiones, regularon la carrera profesional de oficiales y suboficiales: Ley 4707 Orgánica del Ejército (1905), Ley 5043 (1907) -que modificó parcialmente la Ley 4707- la Ley 9675 (1915) y la Ley 11.079 (1922), que introdujo cambios en la anterior. Y se aprobó la Ley 11266 de armamentos (1923), que efectivizó una significativa incorporación de materiales para el Ejército ${ }^{(1,2,3)}$.

Por su parte, la historia de la medicina ${ }^{(4)}$ y la historia social de la salud y la enfermedad $^{(5,6,7,8,9)}$ han reconocido interconexiones entre Ejército, universidad, hospital público y ejercicio privado de la medicina en la Argentina del siglo XIX y en las primeras décadas del siglo XX. Algunas dimensiones del estudio de la sanidad militar han sido abordadas por Gabriela Dalla-Corte Caballero y Miguel Ángel De Marco en su investigación sobre la experiencia del médico argentino Carlos de Sanctis como voluntario con el grado de capitán en el Ejército de Paraguay en la Guerra del Chaco entre 1932-1933 y como oficial de reserva en las grandes maniobras del Ejército argentino de 1936 como médico del Regimiento de Infantería $11^{(10)}$.

Pero a pesar de estas indispensables contribuciones al estudio del tema, nuestro conocimiento actual continúa centrado en el desempeño de los médicos y la medicina en los medios civiles, antes que en la esfera militar. Es por ello que es necesario profundizar en la comprensión de los perfiles y trayectorias académicas y profesionales de médicos, farmacéuticos, dentistas y enfermeros en relación con las doctrinas militares y de defensa, y con sus inscripciones y actividades en las organizaciones, funciones y despliegue de las Fuerzas Armadas.

Teniendo en cuenta lo antedicho, este artículo tiene por objetivos: 1) caracterizar el proceso de modernización, burocratización y profesionalización del Ejército en sus relaciones con las concepciones de la defensa, organización, funciones y despliegue territorial; y 2) analizar, en el marco de ese proceso, la conformación del servicio de sanidad militar entre 1888, con la sanción de la Ley Orgánica del Cuerpo de Sanidad del Ejército y la Armada, y 1938, con los cambios en el diseño orgánico del Ejército en vísperas de la Segunda Guerra Mundial. Me serviré de una metodología cualitativa de análisis de fuentes institucionales: colecciones de leyes y decretos militares, memorias de guerra y Marina, reseñas históricas y orgánicas del Ejército, Anales de Sanidad Militar, Boletín de Sanidad Militar y Revista de la Sanidad Militar.

Siendo el estudio de la sanidad militar en la historia de las Fuerzas Armadas Argentinas en el siglo XX un tema de vacancia para la historiografía y, más ampliamente, para las ciencias sociales, este trabajo contribuye a definirlo como un objeto de conocimiento académico específico, legítimo y relevante, no solo para las investigaciones en historia militar, sino para la historia social de la salud y la enfermedad y los estudios sociales de las burocracias profesionales e intelectuales de Estado en el período analizado (1888$1938)^{(11,12)}$. A tal efecto, se asume como presupuesto que no es posible comprender la historia de la sanidad militar sin inscribirla 
correctamente en la organización, las funciones y el despliegue militar, así como en el marco de las concepciones y prácticas institucionales y profesionales castrenses específicas, de las cuales han sido, y son, un componente indispensable. En esto consiste el principal aporte sustantivo original de este artículo.

\section{DISEÑO ORGÁNICO DEL EJÉRCITO ARGENTINO ENTRE PRINCIPIOS DEL SIGLO XX Y LA DÉCADA DE 1930}

Diversos autores sostienen que, en la primera mitad del siglo XX, el diseño orgánico del Ejército Argentino respondía a la concepción de la denominada "doctrina de la defensa nacional", que concebía a las Fuerzas Armadas como componente específico de defensa externa, integradas en el conjunto de la "nación en armas" y atendiendo hipótesis de conflicto vecinales, principalmente con Brasil y Chile, en el marco de una concepción de la "guerra convencional" que comprometía el esfuerzo de la sociedad nacional en su conjunto ${ }^{(13,14,15)}$. Desde esa concepción y siguiendo el pensamiento estratégico del militar alemán Colmar von Der Goltz, los oficiales del Ejército comprendieron imperiosamente con la Primera Guerra Mundial que la "guerra requiere de todas las fuerzas morales y materiales de la nación"(16,17,18,19). Entendían que era necesario no solo desarroIlar capacidades industriales y militares básicas, autónomas de la Nación, sino proveer bienestar al conjunto de la sociedad argentina, pues la defensa nacional y el esfuerzo de guerra requerían de la integración social y política y de la fortaleza física y espiritual de los ciudadanos. Fueron esas concepciones las que nutrieron el pensamiento y el accionar público de militares como Enrique Mosconi, Manuel Savio, Alonso Baldrich y Juan Domingo Perón, entre otros ${ }^{(20)}$. De allí que los conceptos de "soberanía política, independencia económica y justicia social" de la doctrina política y social de este último abrevaran también de aquella doctrina militar de la "defensa nacional"(21,22,23,24). Sus principios quedarían plasmados en la Ley 13234 de Organización de la Nación en tiempo de guerra, de 1948, que fueron adoptados también en tiempos de paz ${ }^{(25)}$.

Otras interpretaciones historiográficas enfatizaron otras causas en la definición del diseño orgánico del instrumento militar terrestre: unas, destacando la función preponderante del Ejército en la construcción y consolidación del poder presidencial entre 1890 y $1912^{(26)}$; otras, poniendo el acento en el rol intervencionista en la política que tuvo el Ejército entre 1930 y 1983 en la definición de sus misiones, organización y despliegue $^{(27,28)} ; y$, otras, atribuyendo importancia al reclutamiento de la tropa en las jurisdicciones provinciales de todo el país ${ }^{(29,30)}$.

Asimismo es posible que las explicaciones que invocan las hipótesis de conflicto vecinales en la configuración del diseño del instrumento militar terrestre, las que destacan los roles eminentemente políticos cumplidos por el Ejército y aquellas que ponderan la captación de recursos humanos, no sean necesariamente excluyentes, sino que alternativamente guardan una eficacia interpretativa situacional en la comprensión de ideas y comportamientos de distintos actores castrenses en diferentes circunstancias. Dicho en otros términos, resulta plausible considerar que, entre fines del siglo XIX y mediados del siglo XX, fueron las hipótesis de conflicto vecinales las que definieron y orientaron el diseño de fuerza estratégico del Ejército en el marco de la noción de "nación en armas", aun cuando aquel diseño también pudiera ser funcional hasta 1930 con las necesidades políticas de consolidación del poder presidencial y/o desde entonces con las ambiciones intervencionistas en la política de unas conducciones castrenses relativamente autonomizadas del poder político civil.

Ahora bien, ¿cómo eran la organización y el despliegue en divisiones del Ejército entre principios del siglo XX y la década de 1930 ? Las divisiones eran organizaciones militares autónomas entre sí, compuestas por unidades de diferentes armas, elementos de apoyo de combate y de servicios. Entre estos 
últimos se contaba el servicio de Sanidad Militar que actuaba en unidades operativas, en los distritos militares que se ocupaban del reconocimiento de los ciudadanos para el servicio militar obligatorio y en hospitales militares de las cinco divisiones.

En 1905, el diseño orgánico y el despliegue del Ejército estaba conformado por cinco regiones militares: $1{ }^{a}{ }^{\text {Región Militar (Capital }}$ Federal), 2. ${ }^{a}$ Región Militar (Sur), 3. ${ }^{\text {a }}$ Región Militar (Litoral), $4 .^{\text {a }}$ Región Militar (Centro y Cuyo) y $5 .{ }^{a}$ Región Militar (Norte); en tanto los Territorios Nacionales dependían directamente del Ministerio de Guerra. En 1916, las regiones militares pasaron a denominarse divisiones del Ejército. En 1917, las cinco divisiones eran (Tabla 1): 1. ${ }^{\text {a }}$ División (Capital Federal), 2. ${ }^{a}$ División (Patagonia), 3. ${ }^{\mathrm{a}} \mathrm{Di}-$ visión (Mesopotamia), 4. ${ }^{\text {a }}$ División (Cuyo) y 5. ${ }^{a}$ División (Noroeste). Cada división estaba integrada por dos brigadas de infantería, una brigada de caballería (excepto la 3. ${ }^{\text {a }}$ División que poseía dos brigadas de caballería y un regimiento de gendarmería), una brigada de artillería, un comando de ingenieros y distritos militares ${ }^{(31)}$.

En la década de 1920 se produjeron ajustes en este diseño con las reformas del general Agustín Pedro Justo como ministro de Guerra en la presidencia de Marcelo T. de Alvear. De acuerdo con Hernán Cornut, esos ajustes resultaron de la incidencia de tres factores: 1) el proceso de burocratización profesional iniciado a comienzos del siglo XX e intensificado desde 1923 debido a la conflictiva situación regional en el Cono Sur; 2) el pensamiento propio de los oficiales de esa fuerza conforme a las interpretaciones y lecciones aprendidas de la Primera Guerra Mundial; 3) la conflictividad de la Argentina con Brasil y Chile que, en las perspectivas castrenses de la época, requería del logro de un equilibrio militar en el marco de una concepción de disuasión preventiva y preservación de los recursos estratégicos ${ }^{(3)}$.

Hacia 1930 existían cinco divisiones: $1 .^{\text {a }}$ División (con comando en Capital Federal), 2. ${ }^{a}$ División (Campo de Mayo), 3. ${ }^{\text {a }}$ División (Paraná), 4. ${ }^{\mathrm{a}}$ División (Córdoba) y $5 .^{\mathrm{a}}$ División (con comando en Tucumán y, desde
1931, en Salta). El diseño en divisiones tenía por fin: a) ejercitar el mando sobre las unidades de tropa del Ejército Permanente acantonado en su ámbito territorial; b) dirigir la instrucción y preparación para la guerra de las reservas del Ejército Permanente cuando fueran convocadas para ese fin; c) prever y preparar la movilización al pie de guerra de la división y parte de otras divisiones; d) dirigir el enrolamiento y reclutamiento militar de su jurisdicción; e) apoyar y fomentar el desarrollo del tiro ciudadano; y f) descentralizar el abastecimiento de sus unidades dependientes. Como muestra la Tabla 2, cada división desarrolló un entramado burocrático más complejo y especializado a nivel de la provisión de servicios. Su estructura orgánica quedó conformada por: Comando de División, Inspección de Distritos Militares, Comando de Infantería, Comando de Artillería, Justicia de Instrucción Militar, Estado Mayor (secciones de Operaciones, Informaciones y Servicios), Servicios Administrativo, Sanitario y Veterinario, Auditoría, Capellanía y Escolta. A su vez, cada División poseía tres regimientos de infantería, una unidad de caballería o sección de exploradores, una de artillería y una de ingenieros, los distritos militares, parques y trenes, stands de tiro y hospitales militares $^{(31)}$.

En 1938, el diseño orgánico del Ejército cambió una vez más, organizándose en dos Comandos de Ejército, un Comando de Caballería y un Comando de las Fuerzas Aéreas. Del Comando del Primer Ejército dependían la $1 .{ }^{\text {a }}$ División, la $2 .{ }^{\text {a }}$ División y la $3 .^{\text {a }}$ División con comando en Buenos Aires, La Plata (en reemplazo de Campo de Mayo) y Paraná, respectivamente. Del Comando del Segundo Ejército dependían la 4. ${ }^{\text {a }}$ División (Córdoba), 5. ${ }^{\text {a }}$ División (Salta), 6. ${ }^{a}$ División (creada en 1936-1937 con comando en Bahía Blanca y, desde 1938, en Neuquén), el Destacamento de Montaña Cuyo y el Destacamento de Montaña Norte (este último con comando en Salta hasta 1938 y desde entonces en Jujuy). Del Comando de Caballería dependían la 1. ${ }^{a}$ División (Buenos Aires), la 2. ${ }^{a}$ División (Concordia), la Brigada de Caballería $V$ y la Brigada de Caballería VII. La 1. ${ }^{a}$ División y 
Tabla 1. Unidades de las divisiones de Ejército, Argentina, 1917.

\begin{tabular}{|c|c|c|}
\hline División & Brigada & Unidades \\
\hline \multirow[t]{8}{*}{ 1. (Capital Federal) } & I Brigada de Infantería & $\begin{array}{l}\text { Regimiento de Infantería } 1 \\
\text { Regimiento de Infantería } 2\end{array}$ \\
\hline & II Brigada de Infantería & $\begin{array}{l}\text { Regimiento de Infantería } 3 \\
\text { Regimiento de Infantería } 4\end{array}$ \\
\hline & IV Brigada de Infantería & $\begin{array}{l}\text { Regimiento de Infantería } 7 \\
\text { Regimiento de Infantería } 8\end{array}$ \\
\hline & VI Brigada de Infantería & $\begin{array}{l}\text { Regimiento de Infantería } 11 \\
\text { Regimiento de Infantería } 12\end{array}$ \\
\hline & I Brigada de Caballería & $\begin{array}{l}\text { Regimiento de Caballería } 1 \\
\text { Regimiento de Caballería } 8\end{array}$ \\
\hline & I Brigada de Artillería & Regimiento de Artillería Montada 1 \\
\hline & Comando de Ingenieros & I Batallón de Zapadores Pontoneros y Sección de Tren de Puente 1 \\
\hline & Distritos Militares & (cuatro) \\
\hline \multirow[t]{5}{*}{ 2.ㄹ (Patagonia) } & III Brigada de Infantería & $\begin{array}{l}\text { Regimiento de Infantería } 5 \\
\text { Regimiento de Infantería } 6\end{array}$ \\
\hline & II Brigada de Caballería & $\begin{array}{l}\text { Regimiento de Caballería } 2 \\
\text { Regimiento de Caballería } 10\end{array}$ \\
\hline & II Brigada de Artillería & $\begin{array}{l}\text { Regimiento de Artillería Montada } 3 \\
\text { Regimiento de Artillería } 1 \text { (Obuses) }\end{array}$ \\
\hline & Comando de Ingenieros & II Batallón de Zapadores Pontoneros y Sección de Tren de Puente 2 \\
\hline & Distritos Militares & (catorce) \\
\hline \multirow[t]{7}{*}{ 3. ${ }^{a}$ (Mesopotamia) } & V Brigada de Infantería & $\begin{array}{l}\text { Regimiento de Infantería } 9 \\
\text { Regimiento de Infantería } 10\end{array}$ \\
\hline & III Brigada de Caballería & $\begin{array}{l}\text { Regimiento de Caballería } 3 \\
\text { Regimiento de Caballería } 6\end{array}$ \\
\hline & VI Brigada de Caballería & $\begin{array}{l}\text { Regimiento de Caballería } 9 \\
\text { Regimiento de Caballería } 11\end{array}$ \\
\hline & III Brigada de Artillería & $\begin{array}{l}\text { Regimiento de Artillería Montada } 3 \\
\text { I Grupo de Artillería a Caballo }\end{array}$ \\
\hline & Comando de Ingenieros & III Batallón de Zapadores Pontoneros y Sección de Tren de Puente 3 \\
\hline & Regimiento de Gendarmería & \\
\hline & Distritos Militares & (trece) \\
\hline \multirow[t]{6}{*}{ 4. ‥ (Cuyo) } & VII Brigada de Infantería & $\begin{array}{l}\text { Regimiento de Infantería } 13 \\
\text { Regimiento de Infantería } 14\end{array}$ \\
\hline & VIII Brigada de Infantería & $\begin{array}{l}\text { Regimiento de Infantería } 15 \\
\text { Regimiento de Infantería } 16\end{array}$ \\
\hline & IV Brigada de Caballería & $\begin{array}{l}\text { Regimiento de Caballería } 4 \\
\text { Regimiento de Caballería } 7\end{array}$ \\
\hline & IV Brigada de Artillería & $\begin{array}{l}\text { Regimiento de Artillería Montada } 4 \\
\text { I Grupo de Artillería de Montaña }\end{array}$ \\
\hline & Comando de Ingenieros & IV Batallón de Zapadores Pontoneros y Sección de Tren de Puente 4 \\
\hline & Distritos Militares & (diez) \\
\hline \multirow[t]{6}{*}{ 5. (Noroeste) } & IX Brigada de Infantería & $\begin{array}{l}\text { Regimiento de Infantería } 17 \\
\text { Regimiento de Infantería } 18\end{array}$ \\
\hline & X Brigada de Infantería & $\begin{array}{l}\text { Regimiento de Infantería } 19 \\
\text { Regimiento de Infantería } 20\end{array}$ \\
\hline & V Brigada de Caballería & $\begin{array}{l}\text { Regimiento de Caballería } 5 \\
\text { Regimiento de Caballería } 12\end{array}$ \\
\hline & V Brigada de Artillería & $\begin{array}{l}\text { Regimiento de Artillería Montada } 5 \\
\text { II Grupo de Artillería de Montaña }\end{array}$ \\
\hline & Comando de Ingenieros & V Batallón de Zapadores Pontoneros y Sección de Tren de Puente 5 \\
\hline & Distritos Militares & (diez) \\
\hline
\end{tabular}


Tabla 2. Unidades de las divisiones del Ejército. Argentina, 1930.

\begin{tabular}{|c|c|}
\hline División & Unidades \\
\hline 1.. (Comando en Capital Federal) & $\begin{array}{l}\text { Regimiento de Infantería } 1 \\
\text { Regimiento de Infantería } 2 \\
\text { Regimiento de Infantería } 3 \\
\text { Regimiento de Granaderos a Caballo } \\
\text { Regimiento de Artillería } 1 \\
\text { Zapadores-Pontoneros I } \\
\text { Parques y trenes } \\
\text { Distrito Militare 1, 2, 3, 4, } 1 \text { complemento } \\
\text { Stands de tiro }\end{array}$ \\
\hline 2.. (Comando en Campo de Mayo) & $\begin{array}{l}\text { Regimiento de Infantería } 5 \\
\text { Regimiento de Infantería } 6 \\
\text { Regimiento de Infantería } 7 \\
\text { Regimiento de Artillería } 2 \\
\text { Zapadores-Pontoneros II } \\
\text { Parques y trenes } \\
\text { Distrito Militar } 15,17,18,19,24,25,26,13,14,16,20,21,22,23,65,66,68 \\
\text { Regimiento } 8 \text { Montada } \\
\text { Hospital Militar Divisionario } \\
\text { Stands de tiro }\end{array}$ \\
\hline 3.․ (Comando en Paraná) & $\begin{array}{l}\text { Regimiento de Infantería } 9 \\
\text { Regimiento de Infantería } 11 \\
\text { Regimiento de Infantería } 12 \\
\text { Regimiento de Caballería } 3 \\
\text { Regimiento de Artillería } 3 \\
\text { Ingenieros-Zapadores. Pontoneros III } \\
\text { Parques y trenes } \\
\text { Distrito Militar 28, 30, 32, 33, 36, 27, 29, 31, 35, 37, 38, 39, 40, } 67 \\
\text { Regimiento } 10 \text { Montada } \\
\text { Intendencia de Guerra } \\
\text { Hospital Militar Divisionario } \\
\text { Stands de tiro }\end{array}$ \\
\hline
\end{tabular}

4. (Comando en Córdoba)

5.a (Comando en Tucumán y desde 1931 Salta)
Regimiento de Infantería 13

Regimiento de Infantería 14

Regimiento de Infantería 15

Regimiento de Artillería 4

Zapadores-Pontoneros IV

Distrito Militar 41, 42, 43, 44, 45, 46, 47, 48, 49, 50, 51, 52

Destacamento Montaña Cuyo: Regimiento de Infantería de Montaña 16 / Sección de Exploraciones Baqueanos 1 / Grupo de Artillería de Montaña 8

"Coronel Pedro Regalado de la Plaza" / Compañía de Zapadores de Montaña 1 Intendencia de Guerra

Hospital Militar Divisionario

Stands de tiro

Regimiento de Infantería 17

Regimiento de Infantería 18

Regimiento de Infantería 19

Regimiento de Caballería 5

Regimiento de Artillería 5

Zapadores-Pontoneros V

Distrito Militar 53, 54, 55, 56, 57, 58, 59, 60, 61, 62, 63, 64

Destacamento de Montaña Norte: Regimiento de Infantería de Montaña 20 "Cazadores de los Andes" / Sección Exploraciones Baqueanos 2 / Grupo de Artillería de Montaña 5

Intendencia de Guerra

Hospital Militar Divisionario

Stands de tiro 
la 2. ${ }^{\text {a }}$ División de Caballería se completaron con unidades de artillería, zapadores, comunicaciones y servicios ${ }^{(31)}$.

La lectura de estas páginas seguramente resulta esforzada para lectores no familiarizados con la historia militar; sin embargo, su exposición es fundamental para el estudio de la sanidad militar y no constituye un desvío respecto del tema central del artículo. Retengamos esta compleja trama organizativa desplegada en el territorio nacional y formulémonos las preguntas que se hacían las conducciones castrenses de la época: ¿cómo dotar a cada una de las unidades operativas, institutos, comandos y distritos militares de médicos, farmacéuticos, dentistas, veterinarios, enfermeros y otros auxiliares de sanidad que dispongan de conocimientos y prácticas de su disciplina y cuenten con saberes y experiencias específicos para desempeñarse en las organizaciones castrenses en tiempos de paz y de guerra?; ¿cómo proveer las divisiones del Ejército de un hospital militar regional o divisionario en su jurisdicción que atiendan las necesidades del personal? En el siguiente apartado veremos cómo respondieron a estas preguntas entre 1888 y 1938.

\section{La Sanidad Militar en el Ejército}

La historia militar producida en Argentina sitúa tradicionalmente la génesis de la sanidad militar en el Río de la Plata con la creación del Protomedicato por Carlos III o con la impartición del que es considerado el primer curso de medicina en Buenos Aires por el doctor Cosme Argerich en $1801^{(32)}$. En tanto la historia de la medicina destacó el papel de la Sanidad Militar en la formación académica y ejercicio profesional de los médicos y en la producción de conocimientos y prácticas que influyeron en la salud pública del Río de la Plata, Argentina, desde principios del siglo XIX con el Protomedicato, el Instituto Médico Militar, la participación de los médicos en la Guerra de la Independencia, en la Guerra del Brasil, en la Guerra de la Triple Alianza contra el Paraguay, en la "Campaña al Desierto" y en campañas navales.
Sin embargo, el proceso de modernización, burocratización y profesionalización de la Sanidad Militar alcanzó su formalización en el contexto de la organización del instrumento militar terrestre del Estado nacional argentino, con el reglamento provisorio inicial del cuerpo médico militar de 1881 -elaborado por el cirujano mayor Eleodoro Damianovich, jefe del Cuerpo de Sanidad desde 1888 e inspector general de Sanidad entre 1892 y 1897 - y con la sanción de la Ley 2377, Ley Orgánica del Cuerpo de Sanidad del Ejército y la Armada de 1888, reglamentada por primera vez el 24 de octubre de 1891, que otorgó "estado militar" a todo el personal de sanidad y creó un Cuerpo de Sanidad del Ejército y otro de la Armada conformado por médicos, farmacéuticos, dentistas y veterinarios. Hasta entonces, los profesionales que cumplían funciones en la sanidad militar eran considerados -según una expresión de 1938- como "simples empleados administrativos"(33).

Las autoridades del Cuerpo de Sanidad Militar, la Inspección General de Sanidad y la Dirección General de Sanidad del Ejército entre 1888 y 1938 fueron los médicos militares: Eleodoro Damianovich (1888-1997), José María Cabezón (interino, 1897), Alberto Costa (1897-1900), Marcial V. Quiroga (1900-1905), Carlos L. Villar (1905), Marcial V. Quiroga (1905-1907), Francisco de Veyga (1907-1910), Pacífico Díaz (interino, 19101914), Isidro Lobo (interino, 1913), Nicómedes Antelo (1914-1922), Julio R. Garino (1922-1929), Leónidas Facio (1929-1930), Alberto Levene (1930.1932) y Eugenio A. Galli (desde 1932 y continuaba en 1938). La Ley Orgánica -reglamentada por primera vez el 24 de octubre de 1891- definió las jerarquías del personal de Sanidad Militar del Ejército adecuándolas al diseño de esa fuerza que se organizaba en divisiones, brigadas y regimientos. De modo tal, se establecieron las siguientes equivalencias entre los oficiales médicos del Cuerpo de Sanidad y los oficiales del Cuerpo Comando ${ }^{(31)}$ :

- cirujano general/general de brigada

- cirujano de ejército/coronel 
- cirujano de división/teniente coronel

- cirujano de brigada/mayor

- cirujano de regimiento/capitán

- cirujano de cuerpo/teniente $1 .^{\circ}$.

De acuerdo con la Ley Orgánica y sus reglamentaciones, para incorporarse como oficiales del Cuerpo de Sanidad Militar era preciso acreditar diploma médico o bien justificar condición de alumno de la Facultad de Medicina. Los médicos, farmacéuticos y veterinarios diplomados debían rendir un examen de aptitudes físicas, cualidades morales, conocimiento de los reglamentos y disposiciones militares, concernientes al servicio, y demostrar preparación técnica profesional relativa al servicio de sanidad. Si por las necesidades del servicio o por otras causas perentorias fueran dados de alta sin reunir alguno de esos requisitos, eran dados de alta "en comisión" y en el curso de un año debían regularizar su situación personal ${ }^{(34)}$. En tanto que los estudiantes de Medicina podían ser incorporados mientras cursaban el $4 .^{\circ}, 5 .^{\circ}, 6 .^{\circ}$ o $7 .^{\circ}$ año de estudios universitarios. Los médicos iniciaban su carrera militar con el grado de teniente primero, es decir, con dos grados más de jerarquía que los oficiales del Cuerpo Comando que empezaban su carrera como subteniente y, luego, teniente. Asimismo, como oficiales superiores, los médicos militares no alcanzaban las máximas jerarquías como general de división y teniente general. Los ascensos al grado inmediatamente superior de los oficiales de sanidad eran por concurso, respetando la antigüedad en el grado y se otorgaban después de tres años de servicio activo como mínimo en el grado inmediato inferior ${ }^{(31)}$.

A pesar de estos progresos normativos e institucionales, en la Memoria de Guerra y Marina de 1885 se mencionaban dificultades del Ejército para reclutar médicos y estudiantes de medicina, con lo cual, el servicio de sanidad padecía de una crónica falta de personal. También se observaba que ni las remuneraciones percibidas ni las perspectivas de desarrollo de una carrera en el Ejército eran atractivas para los médicos. Se advertía críticamente que el personal disponible en la fuerza eran civiles "asimilados" al Ejército, es decir, sin ninguna o con escasa educación o experiencia profesional militar; en consecuencia, sus servicios como médicos, farmacéuticos, dentistas o veterinarios no estaban preparados enteramente conforme a las necesidades orgánicas y funcionales castrenses en tiempos de paz y mucho menos en tiempos de guerra. La mencionada Memoria consignaba $^{(31)}$ :

Hoy casi todos los cirujanos y farmacéuticos del Ejército son individuos recibidos o diplomados en nuestra Facultad o extranjero, cuyo título profesional revalidan como control de su competencia ante una comisión examinadora, presidida por el cirujano mayor del Ejército y de cuyo examen queda archivada un acta como testimonio. El resto del personal actual lo forman, por lo general, estudiantes aventajados que coronan su carrera médica con el honroso título de cirujano del Ejército.

Vale la pena notar que, medio siglo después, el término "asimilados" continuaba suscitando connotaciones negativas entre oficiales del cuerpo comando para referir a médicos, dentistas, farmacéuticos y veterinarios incorporados como oficiales del cuerpo profesional del Ejército, según recuerda Rodolfo Pasqualini, quien cuenta que el general de división Juan Pistarini, en cierta ocasión, le llamó la atención por haber guardado una "posición poco decorosa" para un oficial en una inspección en la Guarnición Militar de Campo de Mayo. El problema resultaba del hecho que, como Pasqualini no había hecho el servicio militar obligatorio, al iniciar su carrera como médico castrense carecía de los conocimientos militares mínimos como combatiente, incluso de aquellos que normalmente disponía un soldado instruido ${ }^{(35)}$.

En 1875, el ministro de Guerra nombró una comisión integrada por el coronel Luis María Campos y los médicos militares Manuel Biedma y Eduardo Wilde para elegir los terrenos destinados a la construcción del Hospital Militar Central. En 1879 se aprobó el presupuesto para su construcción en 
terrenos localizados al sur de la ciudad de Buenos Aires (calles Caseros y Combate de los Pozos). Las obras se iniciaron en 1882. La supervisión de la construcción estuvo a cargo de los médicos militares Eleodoro Damianovich (Ejército) y Pedro Mallo (Armada), un representante del Departamento Nacional de Higiene y otro del Departamento de Ingenieros. Estaba previsto que el Hospital contara con pabellones aislados unidos por galerías cubiertas (dos pabellones estaban destinados a la Armada), dos salas para oficiales y seis para la tropa (con camas para 264 pacientes, pudiendo aumentarse a 400 sin mayor hacinamiento), sala de cirugía, sala de curaciones, sala para enfermos de cuidados delicados, farmacia, laboratorios, gabinetes de electroterapia y radiografía, sala fotográfica, anfiteatro de autopsias, cámaras mortuorias, departamento de desinfección, horno crematorio de basuras, sala de ropería y limpieza, servicios administrativos, baños (de inmersión, turco, duchas y piscina), cocina central y depósito de alimentos, comedor, economato, amplios jardines, usina de luz eléctrica, agua corriente y sistema de ventilación sin apertura de ventanas. También se dispuso de espacios específicos para las Hermanas de la Caridad (que atendían a los pacientes), la Compañía de Camilleros, el Departamento de Practicantes y el garaje de ambulancias ${ }^{(36)}$. En 1888 se encomendó al médico militar Alberto Costa un estudio sobre la sanidad de los ejércitos en Europa y la compra del instrumental para el Hospital Militar Central en el Reino Unido. A su vez, en 1892 y 1893, Costa viajó a Europa para adquirir el equipamiento para hospitales de campaña/hospitales de sangre ${ }^{(37)}$.

El 20 de marzo de 1889 se inauguró el Hospital Militar Central, aunque el acto oficial se hizo cuando la obra aún estaba incompleta. El médico militar Fernando E. Sotuyo fue nombrado director. Durante su gestión manifestó reiteradamente las dificultades que el servicio debía afrontar por la falta de instrumentos para cirugía, curaciones y de traslado de pacientes como camillas y ambulancias; el Hospital tenía un deficiente sistema de desagües cloacales y de agua corriente, entre otras necesidades ${ }^{(37)}$. Esas dificultades iniciales relacionadas con los problemas edilicios y con la provisión de instrumental hospitalario, fueron relativamente resueltas hacia principios del siglo XX.

El inspector general de Sanidad, doctor Francisco de Veyga, elaboró un decreto -en cuya concepción venía trabajando desde 1907 y que fue aprobado por el presidente José Figueroa Alcorta el 23 de mayo de 1909- que reglamentó la organización de las unidades sanitarias del Ejército para el servicio ordinario en tiempo de paz, fijó el material necesario para constituirlas y las reglas para su aprovisionamiento. Hasta entonces - decía Veyga- las unidades tácticas estaban deficientemente dotadas de materiales hospitalarios y administrativos -medicamentos, desinfectantes, útiles de farmacia, de curación y de escritorio, camas y mesas, etc.- y los recibían desigualmente conforme a los pedidos que cada una hacía a la Inspección General de Sanidad, ocasionando derroches y excesos en unos casos y desabastecimiento en otros. También se proyectó reglamentar la organización y funcionamiento de los Parques Sanitarios Regionales y del Parque Sanitario Central en los que se concentraban y distribuían materiales de sanidad, a efectos de mejorar el sistema de aprovisionamiento de hospitales divisionarios, hospitales de guarnición de $1 .{ }^{\text {a }}$ clase -con más de una unidad-y de $2 .^{\text {a }}$ clase -con una unidad-y las enfermerías de cuerpo para asistencia de enfermos no hospitalizables de tropa ${ }^{(38)}$.

En 1908 se completaron obras de remodelación en el edificio -nuevos baños, duchas, baños turcos, sala de masaje, piscina central, cocina, cuadra de la Compañía de Camilleros- y se inauguraron nuevas salas y equipos del servicio de consultorios externos -clínica médica, oftalmología, otorrinolaringología, dermatología, piel y venéreas, electroterapia y fotografía, odontología- para militares no hospitalizados -en actividad y retirados- y sus familias; en tanto que en 1925 se incorporó el consultorio de ginecología para la familia del personal militar ${ }^{(39,40,41)}$.

Desde principios del siglo XX, el Ejército fue construyendo y desplegando el sistema 
hospitalario militar en el territorio nacional, a efectos de prestar sus servicios al personal de las unidades y comandos en tiempo de paz y de guerra. Ese proceso fue contemporáneo con la construcción de cuarteles destinados a las unidades operativas, en el marco del diseño moderno del Ejército en el que estas quedaban asentadas en una determinada jurisdicción militar, es decir, dejaban de poseer el carácter móvil que habían tenido en el siglo XIX. Así pues, en 1898, se instaló el primer Hospital Militar Divisionario o Regional en la ciudad de Mendoza, en 1902 se instalaron los de Salta y Paraná y, en 1914, el de Tucumán. En 1907, se estableció el Hospital Militar de la 2. ${ }^{a}$ División en la Guarnición Militar de Campo de Mayo $^{(33)}$. Como advertía en 1903 el cirujano de Ejército, doctor José María Cabezón ${ }^{(42)}$ :

Es urgente la necesidad que se siente de que el ejército posea alojamientos cómodos e higiénicos y en suficiente número para vivienda de las tropas y que estén convenientemente situados en la vasta extensión de nuestro territorio. Los actuales cuarteles y hospitales no responden a la higiene moderna y la mayor parte son antiguos, defectuosos, inadecuados, no llenan el objeto para que se les ha destinado. La morbilidad de la tropa disminuirá evidentemente en un grado sensible una vez que el ejército esté dotado de cuarteles confortables e higiénicos, lo que contribuirá también a la disciplina y moralización del soldado.

Para sustanciar adecuadamente ese moderno plan de construcción de cuarteles y hospitales militares -continuaba Cabezón- los médicos del cuerpo de sanidad debían integrar las comisiones que diseñaban los proyectos arquitectónicos, aportando conocimientos y experiencias específicas relativas a la higiene militar: orientación, ventilación e iluminación de los edificios, elección del suelo, materiales de construcción, letrinas, mobiliario, etc. ${ }^{(42)}$.

En 1898, se creó la Escuela de Aplicación de Sanidad Militar dependiente de la Inspección de Sanidad y fue anexada al
Hospital Militar Central para impartir enseñanza teórica y práctica de los médicos, farmacéuticos y veterinarios que, tras iniciar su formación en universidades argentinas o extranjeras, se incorporaban al Ejército contando, como mínimo, con el cuarto año de estudios en Medicina o el primero en Farmacia. Dicha enseñanza no solo estaba orientada al ejercicio médico y de la farmacia en las organizaciones militares y en la guerra, sino a la preparación militar de ese personal "asimilado", que adquiría "estado militar". Los aspirantes continuaban efectuando sus estudios universitarios hasta que se graduaban y estaban obligados a servir en el Ejército por un período no menor de dos años. En noviembre de 1903, la Escuela contaba con un plantel docente de ocho profesores médicos, dos farmacéuticos y dos veterinarios. El cuerpo de estudiantes estaba integrado por: cuatro estudiantes de $7 .^{\circ}$ año de Medicina, cuatro de $6 .^{\circ}$ año, seis de $5 .^{\circ}$ año, siete de $4 .^{\circ}$ año y siete de $3 .^{\circ}$ año; dos estudiantes de $3 .^{\circ}$ año de Farmacia y dos de $2 .^{\circ}$ año; cinco estudiantes de $4 .^{\circ}$ año de Veterinaria, uno de $3 .^{\circ}$ año y dos de $2 .^{\circ}$ año. La formación impartida a los estudiantes -complementaria de la que recibían en la universidad-comprendía materias como Medicina Legal y Legislación Militar, Clínica Quirúrgica y Cirugía de Guerra, Patología Militar, Enfermedades y Epidemias en los Ejércitos, Medicina Operatoria, Bacteriología y Química Aplicada a la Higiene de los Ejércitos, Hipología Superior, y Farmacología ${ }^{(43)}$. La experiencia de esta Escuela, sin embargo, fue discontinuada en 1905 por restricciones presupuestarias. Se propuso como alternativa impartir conferencias sobre contenidos de sanidad militar a los estudiantes que aspiraban a ingresar al cuerpo de sanidad; pero esta propuesta era una solución insatisfactoria. En 1910 se creó por decreto presidencial la Escuela de Aplicación de Medicina Militar -con sede en el Hospital Militar Central- destinada no solo a la formación de médicos, farmacéuticos y veterinarios del servicio de sanidad, sino para dictar cursos de aplicación y perfeccionamiento para el personal en funciones en los diferentes destinos militares y para los oficiales de reserva. 
El plan de estudio para la formación de los estudiantes comprendía, por un lado, materias generales: Instrucción Militar, Administración Militar, Legislación y Medicina Legal Militar, e Higiene Militar; y, por otro lado, materias específicas para los médicos: Patología Militar -enfermedades infecciosas, venéreas y propias del soldado- y Cirugía de Guerra; para farmacéuticos: Farmacología Militar, y Administración Hospitalaria; y para veterinarios: Hipología Militar, Higiene y Patologías Hípicas Militares, y Administración

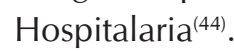

En relación con la formación de los suboficiales auxiliares de sanidad militar, en 1902 se organizó la primera Compañía de CamiIleros con personal de oficiales y de tropa de infantería. En 1904, se creó la Escuela de Enfermeros y, en 1909, la Escuela de Enfermeros y Camilleros y se elaboró un proyecto de organización, reclutamiento, instrucción y ascensos del personal sanitario subalterno del Ejército ${ }^{(45,46)}$. En 1935, la Escuela de Suboficiales de Sanidad -anexa al Hospital Militar Central- comenzó a formar a todos los suboficiales de sanidad: enfermeros, ayudantes de sanidad, ayudantes de farmacia y preparadores $^{(37)}$.

La Tabla 3 presenta la cantidad de oficiales, estudiantes y tropa que dependía del Cuerpo de Sanidad del Ejército en 1903: 76 médicos, 40 farmacéuticos, 2 dentistas, 22 veterinarios, 7 oficiales del cuerpo comando, 41 estudiantes, 57 enfermeros y otros 3 auxiliares de sanidad militar. También 10 médicos civiles ${ }^{(47)}$.

En 1903, este personal estaba destinado en la Inspección General de Sanidad del Ejército, el Hospital Militar Central, el Colegio Militar de la Nación, la Escuela de Tiro, la Escuela de Esgrima, el Ministerio de Guerra, el Depósito Central de Farmacia, el Depósito de Material Sanitario, la Escuela de Aplicación de Sanidad Militar, las Juntas de Excepción para el servicio militar obligatorio en los Distritos Militares y en las unidades militares operativas de las divisiones y brigadas del país. En 1907, los veterinarios se escindieron del Cuerpo de Sanidad y pasaron a depender de la Dirección General de Remonta y Veterinaria. Su análisis merece
Tabla 3. Cantidad de oficiales y tropa dependiente del Cuerpo de Sanidad del Ejército. Argentina, 1903.

\begin{tabular}{|c|c|}
\hline Grado & Cantidac \\
\hline \multicolumn{2}{|l|}{ Oficiales Cuerpo de Sanidad } \\
\hline Inspector general & 1 \\
\hline Cirujano de ejército & 7 \\
\hline Cirujano de división & 9 \\
\hline Cirujano de brigada & 8 \\
\hline Cirujano de regimiento & 16 \\
\hline Cirujano de cuerpo & 34 \\
\hline Cirujano en comisión & 1 \\
\hline Médico civil & 10 \\
\hline Dentista & 2 \\
\hline Farmacéutico inspector & 1 \\
\hline Farmacéutico de ejército & 2 \\
\hline Farmacéutico de 1. ${ }^{-a}$ clase & 2 \\
\hline Farmacéutico de 2.․ clase & 35 \\
\hline Veterinario de 1. ${ }^{\mathrm{a}}$ clase & 1 \\
\hline Veterinario de 2. ${ }^{a}$ clase & 4 \\
\hline Veterinario de 3. ${ }^{a}$ clase & 17 \\
\hline \multicolumn{2}{|l|}{ Auxiliares Cuerpo de Sanidad } \\
\hline Ayudante de dentista & 2 \\
\hline Pedicuro & 1 \\
\hline \multicolumn{2}{|l|}{ Oficiales Cuerpo Comando } \\
\hline Teniente coronel & 1 \\
\hline Mayor & 1 \\
\hline Teniente $2 .^{\circ}$ & 1 \\
\hline Contador & 1 \\
\hline Escribiente & 3 \\
\hline \multicolumn{2}{|l|}{ Compañía de Enfermeros } \\
\hline Enfermero de 1. ${ }^{a}$ clase & 6 \\
\hline Enfermero de 2. . clase & 43 \\
\hline Peón & 3 \\
\hline Cochero & 1 \\
\hline Ordenanza & 2 \\
\hline Encargado de contabilidad & 1 \\
\hline Auxiliar de libros y escribiente & 1 \\
\hline \multicolumn{2}{|c|}{ Estudiantes Escuela de Aplicación de Sanidad } \\
\hline Estudiante 7.ำ año de medicina & 4 \\
\hline 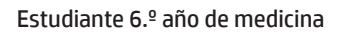 & 4 \\
\hline Estudiante 5. año de medicina & 6 \\
\hline Estudiante $4 .{ }^{\circ}$ año de medicina & 7 \\
\hline 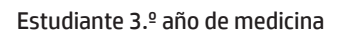 & 7 \\
\hline 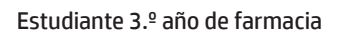 & 4 \\
\hline Estudiante 2.ำ año de farmacia & 2 \\
\hline Estudiante $4 .^{\circ}$ año de veterinaria & 5 \\
\hline Estudiante 3.ำ año de veterinaria & 1 \\
\hline Estudiante 2.ำ año de veterinaria & 1 \\
\hline
\end{tabular}


un estudio específico, pues este cuerpo de sanidad animal -integrado por veterinarios y auxiliares- era decisivo en la organización y funcionamiento de un Ejército hipomóvil.

La dificultosa y conflictiva implementación del servicio militar obligatorio sancionado por la Ley 4301 de 1901 habilitó un proceso organizativo y funcional en el que la sanidad militar era un dispositivo fundamental. Por un lado, porque debía encargarse de la revisión médica practicada a los ciudadanos convocados en cada uno de los distritos militares del país: 46, en 1917, y 68, en 1930. El cumplimiento de esta tarea -someter a una clase de ciudadanos a revisión médica en todo el territorio nacional y en el plazo de unas semanas- obligó al Poder Ejecutivo Nacional a nombrar médicos civiles como integrantes de las Juntas de Excepción Transitorias que exceptuaban a algunos ciudadanos de prestar el servicio militar obligatorio por tener impedimentos psicofísicos, sobre la base del Reglamento de Excepciones al Servicio Militar Obligatorio, aprobado el 30 de noviembre de 1915 y que regulaba las excepciones por causas psicofísicas, objeto de evaluación por parte de los médicos militares y civiles encargados de las revisiones de los ciudadanos de cada clase convocada.

Esos médicos civiles percibían una remuneración mensual por el período que duraran sus servicios ${ }^{(48)}$. Por otro lado, la sanidad militar también era un dispositivo clave porque cumplía funciones en cada una de las unidades operativas, institutos y comandos del Ejército prestando el servicio de sanidad a sus oficiales, suboficiales, soldados, cadetes y aspirantes en tiempos de paz y, eventualmente, en los de guerra.

En 1916, el Ministerio de Guerra se organizó en seis direcciones: Dirección General de Administración, Dirección General del Personal, Dirección General de Arsenales de Guerra, Dirección General de Sanidad, Dirección General de Ingenieros y Dirección General de Tiro.

En el marco de esa reorganización, la Inspección General de Sanidad pasó a conformar la Dirección General de Sanidad del Ejército. También se buscó capitalizar lecciones aprendidas por los ejércitos que participaron de la Primera Guerra Mundial, analizando el desempeño de la sanidad militar; a tal efecto, se relevó material bibliográfico y se enviaron comisiones al exterior para conocer aquellas experiencias, en especial, en lo relativo a la profilaxis de enfermedades infecciosas y la profilaxis de infecciones traumáticas y el tratamiento de heridas de guerra $^{(31,49)}$. En 1920, se presentó un nuevo proyecto de Ley Orgánica de la Sanidad Militar, actualizando el contenido de la que estaba vigente desde 1888, pero no fue aprobado. De acuerdo con el director general de Sanidad, el doctor Nicómedes Antelo, una cuestión que había vuelto inadecuada la Ley vigente -a treinta y dos años de su sanciónera que desde 1901 se había iniciado en el Ejército el proceso de incorporación anual de las clases de ciudadanos por el sistema del servicio militar obligatorio, a quienes debía "ofrecérseles todo género de garantías en materia sanitaria, ya que concurren a cumplir el mandato constitucional del servicio obligatorio, en la más noble previsión de la defensa nacional"(49). Efectivamente, el Ejército debía, por un lado, efectuar los reconocimientos médicos de los ciudadanos de las clases convocadas cada año y, por otro lado, velar por las necesidades sanitarias de la masa de soldados incorporados a las unidades operativas -aquellas unidades consignadas en la Tabla 1 y la Tabla 2 de este artículo-, garantizando la higiene de los cuarteles y acciones de profilaxis en relación con las enfermedades prevalecientes en los ambientes sociales y/o geográficos de procedencia y/o a los cuales eran destinados los conscriptos (venéreas, tuberculosis, paludismo, entre otras) y tratando las enfermedades, traumatismos y afecciones que oficiales, suboficiales y soldados adquirían cumpliendo sus obligaciones militares.

En la Tabla 4 se muestra la cantidad y distribución por destinos de los oficiales de sanidad del Ejército en 1920. Los grados de los oficiales del Cuerpo de Sanidad se consignan -al igual que en la fuente documental original- según sus equivalencias en el Cuerpo Comando(50). Si se compara la cantidad de médicos, farmacéuticos y dentistas 
Tabla 4. Distribución del personal de oficiales de sanidad militar de acuerdo con sus destinos. Argentina, 1920.

\begin{tabular}{|c|c|}
\hline Destino & Cantidad \\
\hline \multicolumn{2}{|c|}{ Dirección General de Sanidad (Capital Federal) } \\
\hline Inspector general (médico) & 1 \\
\hline Teniente coronel (médico) & 2 \\
\hline Capitán (farmacéutico) & 1 \\
\hline Teniente 1.ำ (médico) & 1 \\
\hline Teniente (dentista) & 1 \\
\hline \multicolumn{2}{|c|}{ Junta Superior de Reconocimientos Médicos (Capital Federal) } \\
\hline Coronel (médico) & 1 \\
\hline Teniente coronel (médico) & 1 \\
\hline Mayor (médico) & 1 \\
\hline \multicolumn{2}{|c|}{ Estado Mayor del Ejército (Capital Federal) } \\
\hline Teniente 1.ㅇ (médico) & 1 \\
\hline \multicolumn{2}{|l|}{ Hospital Militar Central (Capital Federal) } \\
\hline Coronel (médico) & 1 \\
\hline Teniente coronel (médico) & 1 \\
\hline Mayor (médico) & 7 \\
\hline Capitán (dentista) & 1 \\
\hline Capitán (farmacéutico) & 1 \\
\hline Teniente 1.ำ (médico) & 7 \\
\hline Teniente $1 . \stackrel{\circ}{\text { (dentista) }}$ & 1 \\
\hline Subteniente (farmacéuticoidóneo) & 3 \\
\hline \multicolumn{2}{|c|}{ 1.ㄹ División (Comando en Capital Federal) } \\
\hline Coronel (médico) & 1 \\
\hline Teniente coronel (médico) & 3 \\
\hline Mayor (médico) & 4 \\
\hline Mayor (farmacéutico) & 1 \\
\hline Capitán (médico) & 7 \\
\hline Capitán (farmacéutico) & 2 \\
\hline Teniente 1.ํ(médico) & 6 \\
\hline Teniente (farmacéutico) & 9 \\
\hline Subteniente (farmacéutico, idóneo) & 3 \\
\hline \multicolumn{2}{|c|}{ 2.ㄹ División (Comando en Campo de Mayo) } \\
\hline Coronel (médico) & 1 \\
\hline Teniente coronel (médico) & 1 \\
\hline Mayor (médico) & 3 \\
\hline Capitán (médico) & 4 \\
\hline Teniente $1^{0}$ (médico) & 1 \\
\hline Teniente $1 \%$ (dentista) & 1 \\
\hline Teniente 1ํo (farmacéutico) & 2 \\
\hline Teniente (farmacéutico) & 3 \\
\hline Subteniente (farmacéutico, idóneo) & 3 \\
\hline \multicolumn{2}{|l|}{ 3.․ División (Comando en Paraná) } \\
\hline Teniente coronel (médico) & 2 \\
\hline Mayor (médico) & 3 \\
\hline Capitán (médico) & 1 \\
\hline 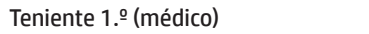 & 9 \\
\hline Teniente (farmacéutico) & 1 \\
\hline Subteniente (farmacéutico, idóneo) & 3 \\
\hline Subteniente (dentista) & 1 \\
\hline \multicolumn{2}{|l|}{ 4.ㄹ División (Comando en Córdoba) } \\
\hline Teniente coronel (médico) & 1 \\
\hline Mayor (médico) & 4 \\
\hline Capitán (médico) & 2 \\
\hline Teniente $1^{\circ}$ (médico) & 5 \\
\hline Subteniente (farmacéutico, idóneo) & 3 \\
\hline \multicolumn{2}{|l|}{ 5.e División (Comando en Tucumán) } \\
\hline Coronel (médico) & 1 \\
\hline Teniente coronel (médico) & 2 \\
\hline Capitán (médico) & 4 \\
\hline Teniente $1^{\circ}$ (médico) & 6 \\
\hline Teniente 1으 (farmacéutico) & 2 \\
\hline Subteniente (farmacéutico, idóneo) & 1 \\
\hline Subteniente (dentista) & 1 \\
\hline
\end{tabular}


entre 1903 (118) y 1920 (91), constatamos que se redujo en 27 miembros. Si tenemos presente que con la sanción de la Ley de Servicio Militar Obligatorio en 1901 fue necesario organizar la revisión médica anual de los ciudadanos de las clases convocados para efectuar dicha prestación militar, es de suponer que la reducción de la cantidad de oficiales de sanidad debe haber tenido un impacto negativo en las capacidades operativas de dicho servicio que, no debemos olvidarlo, también debía proveer de atención al conjunto de los oficiales, suboficiales y soldados del Ejército.

Teniendo en cuenta la necesidad de dotar al servicio de sanidad de una cantidad de oficiales para cumplir adecuadamente con sus prestaciones, por decreto del 3 de enero de 1928, el Poder Ejecutivo Nacional fijó en 203 el número de oficiales del Cuerpo de Sanidad del Ejército: 130 médicos, 54 farmacéuticos y 19 dentistas. La cantidad establecida por decreto superaba los 175 existentes en 1928: 114 médicos, 46 farmacéuticos y 15 dentistas. De acuerdo con el director general de Sanidad, el doctor Julio R. Garino, ese incremento permitiría "regularizar el funcionamiento del servicio, apremiado por la escasez del personal"(51). En 1930, sin embargo, el servicio contaba con 206 oficiales: 130 médicos, 57 farmacéuticos, 19 dentistas y con 225 suboficiales enfermeros y otros auxiliares ${ }^{(31)}$; en 1933, con 206 oficiales: 130 médicos (cuatro cirujanos de ejército, 11 cirujanos de división, 25 cirujanos de brigada, 38 cirujanos de regimiento y 52 cirujanos de cuerpo), 56 farmacéuticos (dos principales, seis de $1 .^{\mathrm{a}}$ clase, 14 de $2 .^{\mathrm{a}}$ clase, diez de $3 .^{\text {a }}$ clase y 24 de $4 .^{\text {a }}$ clase) y 20 dentistas (uno de $1 .^{a}$ clase, cinco de $2 .^{a}$ clase, cuatro de $3 .^{a}$ clase y siete de $\left.4 .^{a}{ }^{\text {clase }}\right)^{(52)} ; \mathrm{y}$, en 1936, con 202 oficiales: 127 médicos (cuatro cirujanos de ejército, 15 cirujanos de división, 27 cirujanos de brigada, 34 cirujanos de regimiento y 47 cirujanos de cuerpo), 57 farmacéuticos (dos principales, cinco de $1 .^{\mathrm{a}}$ clase, 15 de $2 .^{\mathrm{a}}$ clase, 18 de $3 .^{\mathrm{a}}$ clase $\mathrm{y}$ 17 de $4 .{ }^{a}$ clase) y 18 dentistas (uno principal, tres de $1 .^{\mathrm{a}}$ clase, cuatro de $2 .^{\mathrm{a}}$ clase, cinco de $3 .^{a}$ clase y cinco de $4 .^{\text {a }}$ clase). En 1936, había también 221 suboficiales: 139 enfermeros (35 principales, 41 de $1 .{ }^{a}$ clase, 47 de $2 .^{a}$ clase y 16 de $3 .^{a}$ clase), 12 ayudantes de sanidad, cuatro ayudantes de farmacia y 66 preparadores (14 principales, 26 de $1 .^{\text {a }}$ clase, 18 de $2 .{ }^{\text {a }}$ clase y ocho de $3 .{ }^{\text {a }}$ clase $)^{(53)}$.

El personal de sanidad debía atender en 1928 a 2.064 oficiales, 4.983 suboficiales $y$ 21.000 conscriptos y, en 1936, a 2.663 oficiales, 7.000 suboficiales y 35.000 conscriptos. En consecuencia, si consideramos que entre 1928 y 1936 la cantidad de oficiales de sanidad estuvo siempre muy por debajo de los 250 fijados por decreto como aquellos requeridos para atender necesidades y demandas de las unidades operativas, institutos, comandos y distritos militares del Ejército, es de suponer que en esos años persistió la "escasez de personal"(54). No obstante, el director general de Sanidad, doctor Eugenio A. Galli, afirmó en 1938 que no tenían inconvenientes en el reclutamiento de profesionales de sanidad, pero sí problemas de "escasez de recursos materiales imputables, la mayoría de las veces, a las dificultades para hacerlos llegar oportunamente a las zonas requeridas de nuestro extenso territorio" ${ }^{\prime(32)}$.

¿Cómo se distribuía y organizaba el personal de sanidad para prestar servicios en los destinos del Ejército? Veamos algunos casos significativos para 1936. El Regimiento de Caballería 5 (Salta) disponía de un cirujano de cuerpo y un enfermero de 2. ${ }^{a}$. El Regimiento de Caballería 3 (Gualeguay) un cirujano de cuerpo, un enfermero de $3 .^{\mathrm{a}} \mathrm{y}$ un preparador de 2. ${ }^{\text {a }}$ y el Regimiento de Caballería 4 (Villa Mercedes) un cirujano de cuerpo, un farmacéutico de $4 .{ }^{\mathrm{a}}$, un enfermero de $2 .^{\mathrm{a}}$ y uno de $3{ }^{a}$. De modo que, estas unidades emplazadas en el territorio nacional normalmente poseían un oficial médico, auxiliares de sanidad (enfermeros, preparadores y ayudantes) y algún farmacéutico (este último no en todos los casos). ¿Qué sucedía en el comando de una división? El personal era más numeroso, diversificado y de mayor jerarquía militar que el de las unidades operativas antes mencionadas. En la 1. ${ }^{a}$ División (Capital Federal): un cirujano de división, un cirujano de brigada, un farmacéutico de $1 .^{\mathrm{a}}$ y uno de $2 .^{\mathrm{a}}$, un 
dentista de $2 .^{\mathrm{a}}$ y uno de $4 .^{\mathrm{a}}$, un ayudante de farmacia, un preparador de $1 .^{\mathrm{a}}$, uno de $2 .^{\mathrm{a}} \mathrm{y}$ uno de $3 .^{a}$. En la $5 .^{a}$ División (Salta): un cirujano de división, un cirujano de brigada, dos farmacéuticos de $2 .^{a}$, un dentista de $4 .^{a}$ y un enfermero principal. Nótese que los Comandos de División debían cumplimentar el personal de sanidad con oficiales de la jerarquía de cirujano de división y cirujano de brigada, pues eran los grados equivalentes a teniente coronel y mayor -respectivamente- entre los oficiales del Cuerpo Comando que había en ese destino. A su vez, por un lado, en los comandos de división se destinaba al menos un farmacéutico y un dentista (con la excepción en ese año de la 2. ${ }^{a}$ División (Campo de Mayo) que no contaba con un dentista); y, por otro lado, en la Dirección General de Sanidad, en el Hospital Militar Central y en los hospitales divisionarios existía la mayor concentración de cargos cubiertos por médicos de jerarquías superiores: cirujano de ejército, cirujano de división, cirujano de brigada y cirujano de regimiento(53).

La infraestructura hospitalaria del Ejército tuvo progresos entre fines de la década de 1920 y principios de la de 1930 con la construcción de nuevos hospitales divisionarios: el Hospital Militar de la 2. ${ }^{a}$ División (Campo de Mayo); el Hospital Militar de la

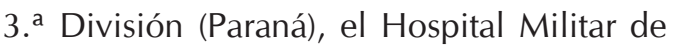

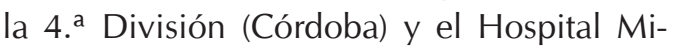
litar de la $5 .^{a}$ División (Tucumán). A partir de 1927, se iniciaron las construcciones de nuevos hospitales militares en las ciudades de Mendoza y Salta; y, en 1936, empezaron las obras del nuevo edificio del Hospital Militar Central "Cirujano Mayor Doctor Cosme Argerich" emplazado en la zona norte de la ciudad de Buenos Aires, en avenida Luis María Campos 726, donde actualmente se encuentra. En 1939, se inauguraron los cuerpos A y B de este hospital ${ }^{(31,55)}$.

En 1936, el Hospital Militar Central y los hospitales divisionarios tenían sus plantas de personal integradas con médicos, farmacéuticos, dentistas y auxiliares. Por ejemplo, el Hospital Militar Central (Capital Federal): un cirujano de ejército, dos cirujanos de división, tres cirujanos de brigada, siete cirujanos de regimiento, tres cirujanos de cuerpo, dos farmacéuticos de $2 .^{a}$ y uno de $3 .^{a}$, un dentista de $1 .^{a}$, uno de $2 .^{a}$ y dos de $3 .^{a}$, cinco ayudantes de sanidad, un ayudante de farmacia, tres enfermeros principales, dos de $1 .^{\mathrm{a}}$, cuatro de $2 .^{\mathrm{a}}$ y uno de $3 .^{\mathrm{a}}$, un preparador de $1 .^{\mathrm{a}}$, cuatro de $2 .^{a}$ y uno de $3 .^{a}$. En términos relativos, los hospitales divisionarios poseían algo menos de personal que el Hospital Militar Central, pero el que menos disponía, el de Tucumán, contaba con un cirujano de brigada, dos cirujanos de cuerpo, dos farmacéuticos de $3 .^{a}$, dos enfermeros principales, uno de $1 .^{\mathrm{a}}$, uno de $2 .^{a}$ y uno de $3 .^{a}$, un preparador principal y dos de $2 .^{a(53)}$. Con la organización de estos hospitales divisionarios, la Dirección General de Sanidad quedó dotada con recursos humanos básicos en las cinco divisiones de Ejército.

\section{REFLEXIONES FINALES}

La historia de la sanidad militar en la Argentina del siglo XX aún no se ha escrito. Disponemos apenas de esbozos producidos por sus protagonistas y algunos conocimientos fragmentarios alcanzados por la historia militar y la historia social de la salud y la enfermedad, refiriendo a algunas de sus instituciones y actores sociales para dar cuenta de las políticas de defensa nacional y las políticas sanitarias en la primera mitad de ese siglo.

Este artículo no viene a completar esa vacancia temática, si bien pone a consideración dos cuestiones relevantes y originales: una de enfoque y otra sustantiva. Por un lado, fundamenta por qué esa historia debe ser hecha en las intersecciones entre la historia militar y la historia social de la salud y la enfermedad. Los beneficios que pone a disposición esta última historiografía para producir una historia de la sanidad militar no sólo radican en sofisticados enfoques y métodos y en los conocimientos reunidos en las últimas tres décadas sobre políticas, instituciones y actores de la salud pública en la Argentina; también permite comprender saberes y prácticas del personal y la prestación 
de servicios de las instituciones castrenses en sus relaciones con la salud pública en las esferas civiles. Ahora bien, al mismo tiempo, es preciso no desatender o descontextualizar la historia de la sanidad militar de sus inscripciones organizacionales, de los esquemas de percepción social y de las experiencias propiamente militares y de la defensa nacional, pues no reparar en esto impediría acceder a la comprensión situacional y específica de las concepciones y prácticas de los médicos, farmacéuticos, dentistas y enfermeros militares.

Por otro lado, el artículo presenta resultados sustantivos básicos y empíricos originales sobre la sanidad militar en el proceso de modernización, burocratización y profesionalización del Ejército entre los años 1888 y 1938. A tal efecto, se identificó la concepción doctrinaria, organizacional, funciones y despliegue territorial de esa Fuerza en ese período y se inscribió la sanidad militar en las mismas a partir de la sanción en 1888 de la Ley Orgánica del Cuerpo de Sanidad del Ejército y la Armada. Se analizó el reclutamiento, la formación, los perfiles profesionales y la cantidad del personal de sanidad destinado a atender las necesidades y demandas de oficiales, suboficiales y soldados de las unidades operativas, institutos, comandos y distritos militares. Se refirió a la construcción y las obras de reforma del Hospital Militar Central y los Hospitales Divisionarios o Regionales, comprendiendo aspectos de la arquitectura, el equipamiento y los servicios hospitalarios. Se advirtió que, entre 1888 y 1938, la sanidad del Ejército fue incrementando sus capacidades y prestaciones; no obstante, ese proceso no fue lineal ni mecánico, dado que se reconocieron -a veces por referencia de sus propias autoridades- dificultades en la provisión de recursos humanos, equipamiento y material médico y farmacéutico, y en las construcciones de los cuarteles y hospitales. En particular, se llamó la atención sobre el hecho de que, aunque el Poder Ejecutivo Nacional fijó en 1928 la cantidad de oficiales médicos, farmacéuticos y dentistas en 250, hasta 1938 el número de esos profesionales con "estado militar" permaneció entre 206 y 202, es decir, por debajo de esa estimación. Dicha escasez relativa ocasionaba no solo problemas a la correcta atención sanitaria de oficiales, suboficiales y soldados del Ejército, sino también en la revisión médica de las clases de ciudadanos convocados anualmente a los distritos militares para prestar el servicio militar obligatorio. El artículo se cierra en 1938 en la antesala de una nueva reformulación del diseño orgánico del Ejército en vísperas de la Segunda Guerra Mundial.

Teniendo en cuenta los resultados alcanzados en este artículo, el próximo objetivo de esta investigación es abordar en profundidad dos cuestiones clave: el análisis de las trayectorias profesionales de personas que se desempeñaron como médicos, farmacéuticos y dentistas del Ejército; y el estudio de los temas centrales de su agenda de conocimientos y formas de intervención en la atención del servicio de sanidad militar entre 1888 y 1938.

\section{REFERENCIAS BIBLIOGRÁFICAS}

1. Ministerio de Defensa. Antecedentes legales y parlamentarios. 1768-1989. Buenos Aires: Ministerio de Defensa; 2009.

2. Domínguez E. Colección de leyes y decretos militares concernientes al Ejército y Armada en la República Argentina: Con anotaciones de modificaciones y derogaciones. Tomo VI. Buenos Aires: Compañía Sud-Americana de Billetes de Banco; 1905.

3. Cornut H. Pensamiento militar en el Ejército Argentino, 1920-1930: La profesionalización, las causas y consecuencias. Buenos Aires: Argentinidad; 2018.

4. Pérgola F. Historia de la medicina argentina: Desde la época de la dominación hispánica hasta la actualidad. Buenos Aires: Eudeba; 2014.

5. González Leandri R. Curar, persuadir, gobernar: La construcción histórica de la profesión médica en Buenos Aires, 1852-1886. Madrid: CSIC; 1999.

6. Ramacciotti K. La política sanitaria del peronismo. Buenos Aires: Biblos; 2009. 
7. Álvarez A. Entre muerte y mosquitos: El regreso de las plagas en la Argentina (siglos XIX y XX). Buenos Aires: Biblos; 2010.

8. Zabala JP. La enfermedad de Chagas en la Argentina: investigación científica, problemas sociales y políticas sanitarias. Bernal: Universidad Nacional de Quilmes; 2010.

9. Buschini J, Zabala JP. La medicina experimental en la Argentina durante la primera mitad del siglo XX: las trayectorias de Ángel Roffo, Salvador Mazza y Bernardo Houssay. Revista Brasileira de História da Ciência. 2015;8(1):22-38.

10. Dalla-Corte Caballero G, De Marco MA. Carlos de Sanctis: Salud, guerra y fraternidad. Rosario: Prohistoria; 2014.

11. Di Liscia MS, Soprano G. Entre espacios grises y aristas brillantes: la categoría burocracia estatal y el estudio de los sistemas de administración pública en la Argentina. En: Di Liscia MS, Soprano G, (eds.). Burocracias estatales: Problemas, enfoques y estudios de caso en la Argentina (entre fines del siglo XIX y XX). Rosario: Universidad Nacional de La Pampa, Prohistoria Ediciones; 2017. p. 9-42.

12. Rodríguez LG, Soprano G. De las profesiones liberales y los intelectuales contra el Estado, al estudio de los profesionales e intelectuales de Estado. En: Rodríguez LG, Soprano G, (eds). Profesionales e intelectuales de Estado: Análisis de perfiles y trayectorias en la salud pública, la educación y las fuerzas armadas. Rosario: Prohistoria; 2018. p. 9-68.

13. López E. Doctrinas militares en Argentina: 1932-1980. En: Moneta C, (comp.). La reforma militar. Buenos Aires: Legasa; 1985. p. 87-112.

14. Sain M. Los votos y las botas. Estudios sobre la defensa nacional y las relaciones civil-militares en la democracia argentina. Buenos Aires: Prometeo; 2010.

15. Montenegro G, Cortese R. La defensa nacional durante el primer peronismo. Doctrinas, estructuras y planeamiento estratégico (1943-1955). Buenos Aires: UMET; 2018.

16. Brown F. La industrialización y la cuestión social: el desarrollo del pensamiento estratégico en Mosconi, Savio y Perón. En: Moreno O, (coord.). La construcción de la Nación Argentina: El rol de las Fuerzas Armadas. Buenos Aires: Ministerio de Defensa; 2010. p. 271-288.

17. García Molina F. La prehistoria del poder militar en la Argentina: La profesionalización, el modelo alemán y la decadencia del régimen oligárquico. Buenos Aires: Eudeba; 2010.
18. Dick E. La profesionalización en el Ejército Argentino (1899-1914). Buenos Aires: Academia Nacional de Historia; 2014.

19. Cornut H. Pensamiento, profesionalización militar y conflicto en el ámbito del ABC a principios del siglo XX. Polhis. 2017;10(20):126-160.

20. Cornut H. Los militares, la industria y el petróleo: Pensar la guerra y la Nación (1923-1930). En: Rodríguez LG, Soprano G, (eds.). Profesionales e intelectuales de Estado: Análisis de perfiles y trayectorias en la salud pública, la educación y las fuerzas armadas. Rosario: Prohistoria; 2018. p.161-184.

21. Galasso N. Perón. Buenos Aires: Colihue; 2005.

22. López E. El primer Perón: El militar antes que el político. Buenos Aires: Capital Intelectual; 2009.

23. Piñeiro Iñiguez C. Perón: la construcción de un ideario. Buenos Aires: Siglo XXI Editores Iberoamericana; 2010

24. Gasió G. El vínculo de unión: Ejército, Policía y Pueblo en los orígenes del Peronismo. Buenos Aires: Teseo; 2012.

25. Ministerio de Defensa. Antecedentes legales y parlamentarios: 1944-1986. Buenos Aires: Ministerio de Defensa; 2010.

26. Quinterno H. Fuego amigo: El ejército y el poder presidencia en Argentina (1880-1912). Buenos Aires: Teseo; 2014.

27. Potash R. El Ejército y la política en la Argentina, 1928-1945: De Yrigoyen a Perón. Buenos Aires: Sudamericana; 1994.

28. Rouquié A. Poder militar y sociedad política en la Argentina. Buenos Aires: Hyspamérica; 1981.

29. Avellaneda A. Del cálculo de las fronteras a la elaboración de un interior: diagnósticos y proyectos sobre el espacio en los cuadros militares argentinos a fines del siglo XIX. Revista Universitaria de Historia Militar. 2016;5(10):242-263.

30. Avellaneda A. Racionalidad militar e ingreso voluntario al Ejército a fines del siglo XIX: Ideas, sueños perdidos e hipótesis de una batalla perdida. Estudios Sociales del Estado. 2017;3(6):124-156.

31. Ejército Argentino. Reseña histórica y orgánica del Ejército Argentino. Vol. 3. Buenos Aires: Círculo Militar; 1972.

32. Pérgola F. Historia de la medicina argentina: Desde la época de la dominación hispánica hasta la actualidad. Buenos Aires: Eudeba; 2014. 
33. Ley No2377 - 1888 - 18 de octubre de 1938: Organización del Cuerpo de Sanidad del Ejército y la Armada a través de cincuenta años. Revista de la Sanidad Militar. 1938:860-862.

34. Decreto del Presidente José Figueroa Alcorta reglamentando la Ley №2377 Orgánica del Cuerpo de Sanidad del Ejército y la Armada. 11 de mayo de 1908. Boletín de Sanidad Militar. 1908; (7):64-65.

35. Pasqualini R. En busca de la medicina perdida. Buenos Aires: Editorial de Belgrano; 1999.

36. De Veyga F. Reseña histórica y descriptiva del Hospital Militar Central. Boletín de Sanidad Militar. 1910;(3):115-121.

37. Ejército Argentino. Reseña histórica y orgánica del Ejército Argentino. Vol. 2. Buenos Aires: Círculo Militar; 1972.

38. De Veyga F. La nueva reglamentación de las unidades sanitarias del Ejército. Boletín de Sanidad Militar. 1909;(8):341-344.

39. Inauguración de nuevos servicios en el Hospital Militar Central. Boletín de Sanidad Militar. 1908;(6):450-451.

40. De Veyga F. Pabellón de aislamiento paras enfermedades infecto-contagiosas. Boletín de Sanidad Militar. 1909;(10):461-465.

41. Giménez R. Hospital Militar Central: Memoria 1910. Boletín de Sanidad Militar. 1910;(9-12):857.

42. Cabezón JM. Construcción de cuarteles y hospitales. Anales de Sanidad Militar. 1903;(11):11011103.

43. Anales de Sanidad Militar. 1903;(12):1153.

44. Decreto del Presidente José Figueroa Alcorta, Creando una Escuela de Aplicación de Medicina Militar. 14 de enero de 1910. Boletín de Sanidad Militar. 1910;(2):95.
45. Schnaibel A. El enfermero militar. Boletín de Sanidad Militar. 1911:9-16.

46. De Veyga F. El personal sanitario subalterno: Proyecto sobre su organización, reclutamiento, instrucción y ascensos. Boletín de Sanidad Militar. 1909;(3):135-141.

47. Ejército Argentino. Anales de Sanidad Militar. 1903; V(VII):673.

48. Decreto 288 del vice-presidente de la Nación en ejercicio del Poder Ejecutivo Nacional. Anales de Sanidad Militar. 1903;(12):1246-1247.

49. Antelo N. Proyecto de Reforma de Ley Orgánica Militar. Revista de la Sanidad Militar. 1920;(13):313-337.

50. Ejército Argentino. Situación de revista del Cuerpo de Sanidad del Ejército. Revista de la Sanidad Militar. 1920;XIX(1-3):135-144.

51. Dirección General de Sanidad Militar. Escalafón de sanidad militar: Reglamentación de la Ley 9675. Revista de la Sanidad Militar. 1928:67.

52. Ejército Argentino. Situación de revista del Cuerpo de Sanidad del Ejército. Revista de la Sanidad Militar. 1933;XXXI(6):128-132.

53. Ejército Argentino. Dirección General de Sanidad: Nómina del personal que integra el Servicio Sanitario. Revista de la Sanidad Militar. 1936: 202-212.

54. Memoria del Ministerio de Guerra 1935-1936. Buenos Aires: Talleres Gráficos del Instituto Geográfico Militar; 1936.

55. Buroni J, Gancedo R. Reseña histórica del Hospital Militar Central. Buenos Aires: Círculo Militar; 1979. 